lation in target organs and to establish the role of aggregated immunoglobulins and heparin in complement activation.

We thank our surgical colleagues Mr J R W Keates and Mr A Forsyth for permission to study patients in their care and all the technical staff of the cardiothoracic unit under the direction of $\mathrm{Mr} \mathrm{A}$ Pastellopoulos. We are grateful to Miss D J Wright for the statistical computations. This study was funded by the British Heart Foundation and by the King's College Hospital joint research committee for locally organised research.

\section{References \\ 1 Parker DJ, Cantrell JW, Karp RB, Stroud RM, Digerness SB. Changes in serum complement and immunoglobulins following cardiopulmonary bypass. Surgery \\ 2 Parker DJ, Cook S, Turner-Warwick $M$. Serum complement studies during and ollowing cardiopulmonary bypass. In: Junod AF, de Haller R, eds. Lung metabolism: proteolysis and anti-proteolysis, biochemical pharmacology, handling of bioactive substances. New York: Academic Press, 1975:481-7. changes in complement associated with cardiopulmonary bypass. $\mathrm{Br} f$ Anaesth $1982 ; 54: 1047-52$. \\ 4 Rent R, Ertel N, Eisenstein R, Gewurz H. Complement activation by interaction of polyanions and polycations. I. Heparin-protamine induced consumption of \\ 5 Hammerschmidt DE, Stroncek DF, Bowers TK, et al. Complement activation and neutropenia occurring during cardiopulmonary bypass. F Thorac Cardiovasc Surg $1981 ; 81: 370-7$. Westaby S. Complement and the damaging effects of cardiopulmonary bypass.}

7 Siegel J, Rent R, Gewurz H. Interactions of C-reactive protein with the complement system. 1. Protamine-induced consumption of complement in acute phase sera. F Exp Med 1974;140:631-47.

8 Pepys NB, Baltz ML. Acute phase proteins with special reference to C-reactive protein and related proteins (pentaxins) and serum amyloid A protein. $A d v$ Immunol 1983;34:141-212.

9 Vergani D, Bevis L, Nasaruddin BA, Mieli-Vergani G, Tee DEH. Clinical application of a new nephelometric technique to measure complement activation. F Clin Pathol 1983;36:793-7.

10 Perrin LH, Lambert PH, Miescher PA. Complement breakdown products in plasma from patients with systemic lupus erythematosus and patients with glomerulonephritis. 7 Clin Invest 1975;56:

11 Chenoweth DE, Cooper SW, Hugli TE, Stewart RW, Blackstone EH, Kirklin JW. Complement activation during cardiopulmonary bypass: evidence for Bosed 1981;304:497-503. during cardiopulmonary bypass, quantitative study of effects of methylprednisolone and pulsatile flow. Br Med f 1983;287:1747-50.

13 Craddock PR, Fehr J, Dalmasso AP, Brigham KL, Jacob HS. Hemodialysis leukopenia: pulmonary vascular leukostasis resulting from complement activation by dialyzer cellophane membranes. F Clin Invest 1977;59:879-88.

4 Dodd NJ, Vergani D, Turney JH, Parsons V, Weston MJ. Complement activation and Clq binding activity in haemodialysis. Proc Eur Dial 7 ransplant Assoc 1981;

5 Hammerschmidt DE, Craddock PR, McCullough J, Kronenberg RS, Dalmasso AP, Jacob HS. Complement activation and pulmonary leukostasis during nylon (1978:51:721-30.

16 Hairston P, Manos JP, Grabner CD, Lee WH Depression of immunologic surveillance by pump-oxygenation perfusion. F Surg Res 1969;9:587-93.

17 White JV. Complement activation during cardiopulmonary bypass. $N$ Engl f Med 1981;305:51.

18 Dale DC, Fauci AS, Guerry D, Wolff SM. Comparison of agents producing a neutrophil leucocytosis in man. F Clin Invest $1975 ; 56: 808-13$.

19 Dodd NJ, Gordge MP, Tarrant J, Parsons V, Weston MJ. A demonstration of neutrophil accumulation in pulmonary vasculature during haemodialysis. Proc
Eur Dial Transplant Assoc 1983;20:186-9.

\title{
Latent anaphylactic sensitisation of infants of low birth weight to cows' milk proteins
}

\author{
A LUCAS, P MCLAUGHLAN, R R A COOMBS
}

\begin{abstract}
Latent systemic anaphylactic sensitisation to cows' milk was assessed in 61 preterm infants who were randomly assigned to receive either a special formula for preterm infants based on cows' milk or banked breast milk or one or other of these as a supplement to maternal milk. A single sample of venous blood was taken near to the time of discharge from the neonatal intensive care unit, and the histamine release by blood basophils in response to in vitro challenge with cows' milk and anti-IgE was measured. Compared with the blood from infants fed on human milk, that from infants fed on preterm formula showed a significant increase in histamine release to challenge with cows' milk, the response being greater in blood from infants of lower birth weight and gestational age. A smaller but significant increase in blood histamine release with anti-IgE challenge was observed in the group fed on preterm formula.

Infants of low birth weight fed on preterm formula based on cows' milk may develop latent systemic sensitisation more rapidly than infants born at term. The clinical importance of this requires further investigation.
\end{abstract}

Dunn Nutrition Unit, Cambridge CB4 1 XJ

A LUCAS, MA, MRCP, Medical Research Council clinical scientist and honorary consultant in paediatrics, Addenbrooke's Hospital

Division of Immunology, Department of Pathology, Addenbrooke's Hospital, Cambridge

P MCLAUGHLAN, PHD, senior research associate, University of Cambridge R R A COOMBS, MRCVS, FRs, Quick professor, University of Cambridge

Correspondence to: Dr A Lucas.

\section{Introduction}

Allergy to cows' milk protein has been studied extensively in term infants; little corresponding information, however, exists concerning infants born preterm, in whom the clinical and physiological conditions under which sensitisation to cows' milk could occur are special. In early postnatal life premature neonates may have increased gut permeability to dietary antigens compared with that seen in term infants. ${ }^{1}$ Moreover, special formulas for preterm infants based on cows' milk, which are being used increasingly in clinical practice, have protein concentrations that are substantially higher than those incorporated into conventional adapted formulas. Finally, infants born near the end of the second trimester may differ from those born at term in the state of development of their immune system. We therefore investigated whether premature infants have an increased (or decreased) risk of becoming sensitised to cows' milk antigens.

We measured histamine release by blood basophils in whole blood after in vitro challenge with cows' milk and anti- $\operatorname{IgE}^{2}$ to assess the development of latent anaphylactic sensitisation in premature infants allocated, randomly, to dietary regimens containing either a formula for preterm infants based on cows' milk or human milk alone.

\section{Patients and methods}

Sixty one infants of low birth weight were assessed at the time of their discharge from the neonatal intensive care unit at this hospital. As part of a larger study they had been allocated randomly to particular diets shortly after birth, as follows: infants whose mothers did not wish to provide their milk were allocated to receive either a formula milk for preterm infants (11 infants) or pasteurised banked donor breast milk (10 infants); infants whose mothers elected to provide their own milk were randomly allocated to receive, as a supplement

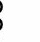


to raw maternal milk, either the preterm formula (21 infants) or banked breast milk (19 infants) to provide a total dietary intake of $180-200 \mathrm{ml} / \mathrm{kg} /$ day. In the groups receiving "supplemented" maternal milk the infants received a variable proportion of their diet as maternal milk according to maternal inclination or success in milk expression (median intake of maternal milk: $42 \%$ of total intake). Infants fed on preterm formula alone had received in total a mean (SE) of 6.4 $(0 \cdot 7)$ litres of this diet before the study, whereas infants receiving preterm formula as a supplement to maternal milk had received only $3.2(0 \cdot 6)$ litres of it before the study. Table I shows the mean birth weight, duration of gestation, and age at the time of study for each of the four groups. The formula used in this study had a protein content of $2 \mathrm{~g} / 100 \mathrm{ml}$ with a casein to whey ratio of 40 to 60 .

Mean (SE) gestational age, birth weight, and age at time of study* for infants receiving one of four dietary regimens

\begin{tabular}{lcccc}
\hline & \multicolumn{4}{c}{ Babies receiving: } \\
\cline { 2 - 6 } & $\begin{array}{c}\text { Preterm } \\
\text { formula } \\
\text { alone } \\
(\mathrm{n}=11)\end{array}$ & $\begin{array}{c}\text { Banked } \\
\text { breast } \\
\text { milk } \\
\text { alone } \\
(\mathrm{n}=10)\end{array}$ & $\begin{array}{c}\text { Maternal } \\
\text { milk } \\
\text { supple- } \\
\text { mented } \\
\text { with } \\
\text { preterm } \\
\text { formula } \\
(\mathrm{n}=21)\end{array}$ & $\begin{array}{c}\text { Maternal } \\
\text { milk } \\
\text { supple- } \\
\text { mented } \\
\text { with } \\
\text { banked } \\
\text { breast } \\
\text { milk } \\
(\mathrm{n}=19)\end{array}$ \\
\hline $\begin{array}{l}\text { Gestation, in weeks } \\
\begin{array}{l}\text { Birth weight, in ge at time of study, in } \\
\text { days* }\end{array}\end{array}$ & $\begin{array}{l}30 \cdot 3(0 \cdot 8) \\
1378(96)\end{array}$ & $\begin{array}{c}29 \cdot 5(0 \cdot 7) \\
1277(116)\end{array}$ & $\begin{array}{c}30 \cdot 8(0 \cdot 6) \\
1442(56)\end{array}$ & $\begin{array}{c}30 \cdot 4(0 \cdot 5) \\
1435(55)\end{array}$ \\
\hline
\end{tabular}

*Just before discharge from hospital, with time to discharge being influenced by diet *Just before disch
and birth weight.

Near the time of discharge (at $1750-2000 \mathrm{~g}$ body weight) a routine heparinised blood sample was taken from each infant. A $1 \mathrm{ml}$ aliquot was stored at $4 \mathrm{C}$ until subjected to the histamine release tests, usually within four hours after collection.

Histamine release tests-The heparinised blood was challenged with a diluted sample of pasteurised cows' milk and with anti-IgE and the released histamine measured as described previously. Histamine release (HR) from whole blood, induced by milk and anti-IgE, was expressed as a proportion $\left({ }^{\circ}{ }_{10}\right)$ of the total available histamine present in the blood cells $(\mathrm{H})$, calculated as follows:

$$
\% \mathrm{HR} \text {-milk or anti-IgE induced HR-PBS control }
$$

\section{$\mathrm{H}-\mathrm{PBS}$ control}

with PBS indicating phosphate buffered saline control.

In view of the appreciably skewed distribution of results, nonparametric tests of significance (two tailed) were used.

\section{Results}

\section{CHALLENGE WITH COW' MILK}

Figure 1 shows the proportion of histamine released from the infants' blood after in vitro challenge with cows' milk for each of the four groups. Blood from eight of the 10 infants allocated to receive banked breast milk alone showed no response at all to challenge with cows' milk, compared with three out of the 11 assigned to receive preterm formula alone. Histamine release by blood basophils was significantly greater in the group fed exclusively on preterm formula $(\mathrm{p}=0.002$, by Mann-Whitney rank sum test, including both " $\mathrm{re}$ sponders" and "non-responders"; fig 1). Taking a histamine release of $9 \%$ or more to be a "positive" response, ${ }^{2}$ four of 11 infants fed on preterm formula alone showed a positive response (and a further infant had a histamine release of $8.5^{\circ}{ }_{0}$ ), whereas none of the 10 infants fed on banked breast milk had a positive response (highest histamine release $2 \cdot 5^{\circ}{ }^{\circ}$ ).

Differences between the blood basophil response to cows' milk in the groups of infants in whom preterm formula and banked breast milk were used as supplements to maternal milk were less considerable, though those receiving banked breast milk as a supplement showed a tendency towards a higher incidence of total non-responsiveness (14 out of 19 compared with 10 out of the 21 receiving preterm formula as a supplement) and a lower overall histamine release (fig 1); neither difference, however, reached significance. One infant who

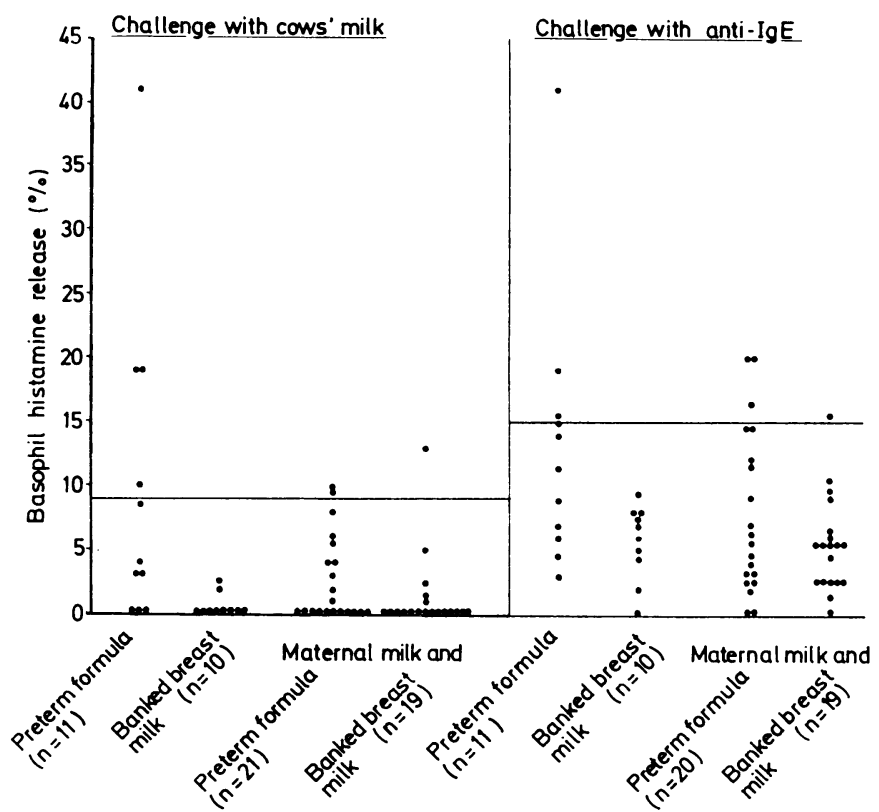

FIG 1 -Blood histamine release after in vitro challenge with cows' milk (left) or anti-IgE (right) in infants randomly assigned to receive one of four dietary regimens. The horizontal lines indicate the proportion of histamine release arbitrarily designated as positive to challenge with cows' milk $\left(90^{\circ}\right)$ or anti-IgE $(15 \%)$.

had been fed exclusively on human milk (maternal milk plus banked breast milk) had a positive response (histamine release $13 \cdot 2 \%$ ).

In the 30 infants who had received preterm formula as their sole diet or as a supplement there was a significant inverse correlation between histamine release by blood basophils to challenge with cows' milk and birth weight or gestational age. In addition, however, there was a positive correlation with the total cumulative volume of preterm formula consumed: after log transformation of the data on histamine release correlation coefficients were, respectively, $\mathrm{r}=-0.42$, $r=-0.40$, and $r=+0.41(p<0.03$; and a similar level of significance was found with Spearman's rank correlation test). Smaller infants, however, spent longer in hospital, and there was an inverse correlation between birth weight (or gestational age) and volume of preterm formula consumed $(p<0.02)$.

\section{CHALLENGE WITH ANTI-IgE}

Figure 1 also shows for each of the four groups the histamine release of whole blood when challenged with anti-IgE. Infants fed on preterm formula alone had a greater blood histamine release than those fed exclusively on banked breast milk ( $p=0.05$ by two tailed Mann-Whitney rank sum test). Taking a histamine release of above $15 \%$ to be a positive response, ${ }^{2}$ four out of 11 infants who were fed on preterm formula alone showed such a response (and a further infant had a histamine release of $\left.14.3^{\circ} \mathrm{o}\right)$; in contrast, none of the infants fed on breast milk had a histamine release of above $15^{\circ}$ (highest $9.3^{\circ} \%$ ). Neither the smaller differences in response between the groups receiving supplemented maternal milk nor the correlations between response to anti-IgE and birth weight, gestational age, and volume of preterm formula consumed reached significance.

\section{Discussion}

The value of measuring histamine release by blood basophils in response to challenge with cows' milk as an index of systemic anaphylactic sensitisation to cows' milk antigens has been discussed elsewhere. ${ }^{2}$ The present study indicated that by a mean postnatal age of 30 days low birthweight infants randomly assigned to receive only a preterm formula based on cows' milk, providing $2 \mathrm{~g}$ protein $/ 100 \mathrm{ml}$, had a greater degree of latent anaphylactic sensitisation than did low birthweight infants receiving banked human milk alone, whose blood showed minimal or no histamine release after challenge with 
cows' milk. In contrast, no significant difference in histamine release was observed between infants fed on preterm formula and those fed on pasteurised donor milk when these diets were used as a supplement to maternal milk. There was, however, a tendency to a higher histamine release when the formula was used as a sole diet compared with when it was used, in smaller quantities, in combination with maternal milk. Although the degree of sensitisation seen in preterm infants may be influenced by the dose of antigen consumed (see below), our findings raised the interesting possibility that the presence of raw milk in the infant's gut may reduce the sensitising effect of cows' milk proteins in this circumstance.

When the 30 infants who had been fed on the preterm formula, either as the sole diet or as a supplement to maternal milk, were considered collectively infants of lower birth weight (fig 2) and lower gestational age had a greater histamine release in response to challenge with cows' milk than did those of greater birth weight and higher gestational age. The smallest infants

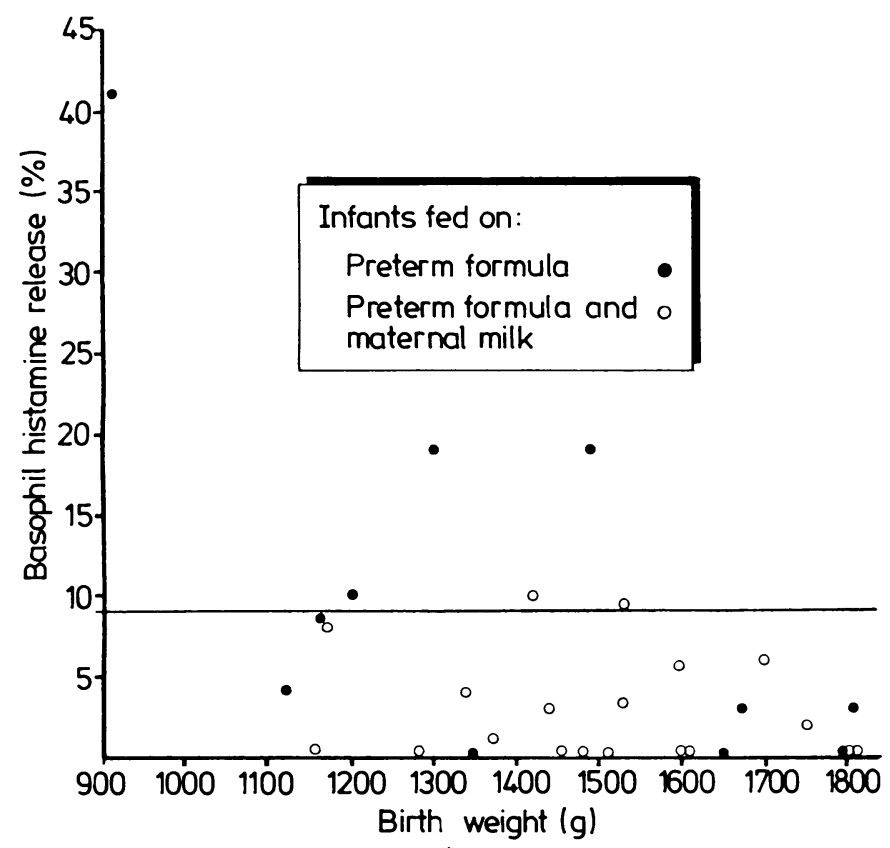

FIG 2-Inverse relation between birth weight and blood histamine release to in vitro challenge with cows' milk in infants fed exclusively on preterm formula and in infants fed on preterm formula as a supplement to maternal milk. The horizontal line at $9 \%$ indicates the arbitrarily designated positive response.

were, however, those who had also received the greatest cumulative volume of preterm formula before the study and intake of preterm formula also correlated with histamine release. This investigation was not designed to examine the effects on blood histamine release of birth weight or quantity of preterm formula consumed, and no firm conclusions could be drawn, but the question raised was whether the increased degree of sensitisation in the smaller infants fed on preterm formula was due primarily to their prematurity and related, perhaps, to their greater gut permeability to dietary antigens, ${ }^{1}$ or to the larger cumulative volume of formula they consumed, perhaps by increasing antigenic exposure.

A release of greater than $9 \%$ of the total content of blood histamine after challenge with cows' milk had been arbitrarily taken to be a positive response-that is, one greater than seen in healthy adult controls. ${ }^{2}$ Of the 19 infants fed on banked breast milk, only one, fed on donor milk as a supplement to maternal milk, had such a response. (We have no data on whether this sensitised infant fed on human milk might have been exposed to cows' milk antigens in utero or via maternal milk postnatally.) In contrast, over a third of infants fed exclusively on preterm formula gave a positive histamine release, and, of the seven who weighed less than $1500 \mathrm{~g}$ at birth, four $(57 \%$ ) had become sensitised to this extent (with a further infant showing an $8.5 \%$ blood histamine release).

Although these present figures are small, it is interesting that in our previous cross sectional study of term infants (seen in clinical practice for a wide range of conditions) ${ }^{2}$ the proportion of subjects showing a histamine release of over $9 \%$ rose during infancy from $22 \%$ at 4-26 weeks old to only $30 \%$ in children over 1 year, most of whom were likely to have been exposed to cows' milk antigens. Epidemiological comparisons between the two studies could be misleading, and we recognise the need for a formal comparison between formula fed term and preterm infants to investigate the possibility raised by our investigations that the rate of development and prevalence of latent anaphylactic sensitisation to cows' milk antigens may be greater in infants born preterm and (perhaps) especially so in those of very low birth weight or gestational age.

In this study we also identified a smaller but significant relation between feeding with formula based on cows' milk and blood histamine release on challenge with anti-IgE. Our previous work (unpublished) has suggested an association between this response and clinical atopy in both children and adults.

A critical factor in interpreting the significance of our data is whether latent systemic sensitisation relates to the later development of clinical manifestations of atopy or cows' milk allergy. At present many preterm infants (of whom a subsample has been considered here), randomised to diet in the neonatal period, are being followed up clinically; one object of this prospective study will be to determine the relation between neonatal feeding practices and the later development of allergic phenomena. In recent years uncertainty over the nutritional adequacy of donor breast milk for feeding babies of low birth weight has resulted in the continued use of standard adapted formulas in many units, together with the development of special cows' milk based formulas designed to meet the calculated nutrient requirements of preterm infants. These newer formulas may confer benefits in terms of postnatal growth performance and biochemical state and are likely to be used increasingly. Clearly the potential role of cows' milk based formulas in the development of allergic disease in infants born preterm should be investigated and measured, and, if indicated, the possibility of rendering such formulas hypoallergenic should be explored.

RRAC and PM received a Medical Research Council project grant. We thank Mrs Gwen Easter for technical help.

\section{References}

1 Roberton DM, Paganelli R, Dunwiddie R, Levinski RJ. Milk antigen absorption in the neonate. Arch Dis Child 1982;57:369-72.

McLaughlan P, Coombs RRA. Latent anaphylactic sensitivity of infants to cows' milk protein: histamine release from blood basophils. Clin Allergy 1983;13:1-9. (Accepted 29 August 1984)

\section{ONE HUNDRED YEARS AGO}

We have received, with increasing frequency of late, complaints as to the inefficient ventilation of the rooms at the General Post Office, in which clerks of different grades work for about six or eight hours daily-about a third of their lives. In some of the rooms, from forty to sixty clerks work; and in the winter time, the heat and noxious effluvia from the burning gas, added to those from the lungs and skin of the workers, form an atmosphere which causes daily headaches in a large proportion, and in many, respiratory troubles which lead to impaired health, and frequent necessity for leave of absence. Complaints, even to the medical officer, are said to endanger promotion, and more than one correspondent has assured us that the influence of the press is the only escape from the difficulty. We sincerely trust the new Postmaster-General will direct his careful attention to the welfare of his subordinates. (British Medical fournal 1884;ii:1149.) 